This is the peer-reviewed version of the following article:

Stojanović, M.; Simović, M.; Mihailović, M.; Veličković, D.; Dimitrijević, A.; Milosavić, N.; Bezbradica, D. Influence of Fatty Acid on Lipase-Catalyzed Synthesis of Ascorbyl Esters and Their Free Radical Scavenging Capacity. Biotechnology and Applied Biochemistry 2015, 62 (4), 458-466. https://doi.org/10.1002/bab.1296.

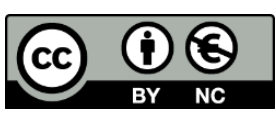

This work is licensed under a Creative Commons - Attribution-NonCommercial 2.0 Generic (CC BY-NC 2.0) 


\section{Influence of fatty acid on lipase-catalyzed synthesis of ascorbyl esters and their free radical scavenging capacity}

Marija Stojanović ${ }^{1}$, Milica Carević ${ }^{1}$, Mladen Mihailović ${ }^{1}$, Dušan Veličković ${ }^{2}$, Aleksandra Dimitrijević $^{2}$, Nenad Milosavić ${ }^{2}$, Dejan Bezbradica ${ }^{1 *}$

${ }^{1}$ Department of Biochemical Engineering and Biotechnology, Faculty of Technology and Metallurgy, University of Belgrade, Karnegijeva 4, 11000 Belgrade, Serbia

${ }^{2}$ Department of Biochemistry, Faculty of Chemistry, University of Belgrade, Studentski trg 12, 11000 Belgrade, Serbia

Running title: Enzymatic synthesis of fatty acid ascorbyl esters

\footnotetext{
* Corresponding author. Dejan Bezbradica, Department of Biochemical Engineering and Biotechnology, Faculty of Technology and Metallurgy, University of Belgrade, Karnegijeva 4, 11000 Belgrade, Serbia. E-mail address: dbez@tmf.bg.ac.rs Tel.: (+38111) 3303727. Fax: (+38111) 3370387.
}

This article has been accepted for publication and undergone full peer review but has not been through the copyediting, typesetting, pagination and proofreading process, which may lead to differences between this version and the Version of Record. Please cite this article as doi: 10.1002/bab.1296. 


\begin{abstract}
Fatty acid ascorbyl esters are recently emerging food, cosmetic, and pharmaceutical additives, which can be prepared in eco-friendly way by using lipases as catalysts. Since they are amphiphilic molecules which possess high free radical scavenging capacity, they can be applied as liposoluble antioxidants, as well as emulsifiers and biosurfactants. In this study, the influence of a wide range of acyl donors on ester yield in lipase-catalyzed synthesis and ester antioxidant activity was examined. Among saturated acyl donors, higher yields and antioxidant activities of esters were achieved when short chain fatty acids were used. Oleic acid gave the highest yield overall and its ester exhibited high antioxidant activity. Optimization of experimental factors showed that the highest conversion $(60.5 \%)$ in acetone was achieved with $5 \mathrm{~g} \mathrm{~L}^{-1}$ of lipase, $50 \mathrm{mM}$ of vitamin $\mathrm{C}$, ten-fold molar excess of oleic acid, and $0.7 \mathrm{~mL} \mathrm{~L}^{-1}$ of initial water. Obtained results showed that even short and medium chain ascorbyl esters could be synthesized with high yields and retained (or even exceeded) free radical scavenging capacity of L-ascorbic acid, indicating prospects of broadening their application in emulsions and liposomes.
\end{abstract}

Keywords: antioxidant, ascorbyl ester, Candida antarctica lipase B, fatty acid, vitamin C

Abbreviations: BHT, butylated hydroxytoluene; BHA, butilated hydroxyanisole; PG, propyl gallate; TBHQ, $t$ butylhydroquinone; GRAS, Generally Recognized as Safe; FA, fatty acid; HLB, hydrophilic lipophilic balance; $\mathrm{O} / \mathrm{W}$, oil in water; W/O, water in oil, CAL B, Candida antarctica lipase B; $\mathrm{a}_{\mathrm{w}}$, water activity. 


\section{Introduction}

Autooxidation of fats and oils is the main cause for shortening of the shelf life of food and cosmetic products containing them. Synthetic antioxidants (butylated hydroxytoluene - BHT, butilated hydroxyanisole - BHA, propyl gallate - PG, and $t$-butylhydroquinone - TBHQ) are most commonly being used as additives in such products, in order to prevent deterioration of lipids, although their potential toxicity is alarming [1]. Therefore, natural antioxidants or their derivatives, which are safe to use, and which have high free radical scavenging capacity and liposolubility, such as fatty acid ascorbyl esters, are preferable. Those compounds are, depending on their hydrophobicity, which can be adjusted by selecting the proper length of ester hydrocarbon chain length, suitable for application in different systems (bulk oil media, emulsions etc.) [2]. In addition, due to their amphiphilic structure, these esters are potential biosurfactants [3] and components for drug nanoparticles formulations [4]. At this moment, ascorbyl palmitate is being commercially produced in the process catalyzed by chemical means, in spite of disadvantages such as low yields and absence of regioselectivity [5]. Also, application of ascorbyl palmitate is limited due to its low solubility in oils [6]. The aforementioned obstacles could be overcome by using unsaturated or shorter chain fatty acid esters of vitamin C produced in enzymatically catalyzed processes.

Lipases (triacylglycerol acylhydrolases, E.C. 3.1.1.3.), besides their application in hydrolysis of triglycerides, are widely used as a biocatalysts in esterification, transesterification, and interesterification reactions [7, 8]. Fatty acid ascorbyl esters were so far synthesized by using several microbial lipases among which lipase from Candida antarctica, type B was most frequently applied [6, 9-11]. Since these reactions were usually performed in low water activity mediums, liquid free forms are usually replaced with immobilized enzyme preparations. Additionally, such forms of biocatalysts could be reused and their application simplifies downstream processing, which altogether significantly lowers the price of the 
process while products of an improved quality are obtained [12]. Oils, saturated and unsaturated fatty acids, and their methyl, ethyl, and vinyl esters were previously utilized, whereas higher yields were achieved if expensive, activated acyl donors were used. Also, fatty acids of different number of carbon atoms were applied [1].

The main objectives of this study were to investigate affinity of lipase from $C$. antarctica towards various fatty acids in synthesis of ascorbyl esters and compare antioxidant activities of obtained esters. Therefore, specificity of applied catalyst towards carboxylic acids was investigated in broader range of acid chain lengths than in any of previous reports. Hence, acetic, caproic, capric, myristic, and stearic acid were used as acyl donors, while oleic acid was applied to examine the effect of double bond on affinity by comparison with stearic acid. The effect of acyl donors was also tested regarding physiological activity of obtained esters determined as free radical scavenging capacity. After selection of the most adequate acyl donor, key experimental factors were optimized on this particular synthesis. Within this part of the study, effects of important experimental parameters (enzyme loading, water content, temperature, and substrates concentration) on product yield were analyzed.

\section{Materials and methods}

\subsection{Enzyme and chemicals}

Lipase B from $C$. antarctica (CAL B) immobilized on acrylic resin, Novozym ${ }^{\circledR} 435$, was purchased from Novozymes (Bagsvaerd, Denmark). L-ascorbic acid $99.7 \%$ pure was purchased from Zorka, Šabac, Serbia. Oleic acid (Ph. Eur., NF pure) was purchased from AppliChem, Darmstadt, Germany. Saturated fatty acids - acetic, caproic, capric, myristic, and stearic, were obtained from Sigma-Aldrich Chemie Gmbh, Steinheim, Germany, all $98 \%$ pure. 2,2-Diphenyl-1-picrylhydrazyl radical (DPPH) and ascorbyl palmitate ( $\geq 99 \%)$ were purchased from Sigma-Aldrich Chemie Gmbh, as well. Following solvents were used as 
reaction media: $t$-butanol (99\%, Sigma-Aldrich Chemie Gmbh, Steinheim, Germany), acetone (99.5 \%, Zorka Pharma, Šabac, Serbia), acetonitrile (p.a., Kemika, Zagreb, Croatia), n-hexane (95-98.5\%, Carlo Erba Reagents, Milano, Italy), and isooctane (99.5\% pure, Centrohem, Stara Pazova, Serbia). Hydranal ${ }^{\circledR}$-solvent and Hydranal ${ }^{\circledR}$-titrant were purchased from Sigma-Aldrich Chemie Gmbh, Steinheim, Germany. HPLC analyses were carried out with methanol and acetonitrile obtained from JT Baker, SAD, and phosphoric acid purchased from Sigma-Aldrich Chemie Gmbh, Steinheim, Germany, all of HPLC grade. Zeolite molecular sieves (diameter $2-3 \mathrm{~mm}$ and $0.4 \mathrm{~nm}$ pores) were used as water adsorbents.

\subsection{The enzymatic synthesis of ascorbyl esters}

Experiments were conducted in $100 \mathrm{~mL}$ capped vials, in a shaker at $250 \mathrm{rpm}$, and at a temperature in the range $40-55{ }^{\circ} \mathrm{C}$. The reaction mixture volume was $10 \mathrm{~mL}$ and it was composed of different amounts of ascorbic acid, fatty acid, enzyme, water, and organic solvent, which are specified for each experiment individually. All solvents were kept with molecular sieves for 24 hours prior to use. Karl-Fischer apparatus (Mettler Toledo, USA) was used for the measurement of water concentration in organic solvents. Volumetric method, titration of the sample dissolved in Hydranal ${ }^{\circledR}$-solvent with the Hydranal ${ }^{\circledR}$-titrant containing $\mathrm{I}_{2}$, was applied. Water content was proportional to the amount of consumed $\mathrm{I}_{2}$. The apparatus consisted of an automated burette, titration vessel, stirrer, and equipment for potentiometric titration.

\subsection{HPLC determination of esterification products}

Akta Purifier HPLC system (Amersham Pharmacia Biotech, Piscataway, NJ, USA) and reverse phase column (Waters Spherisorb ODS 2-C18, $250 \mathrm{~mm} \times 4.6 \mathrm{~mm}, 5 \mu \mathrm{m}$, Milford, MA, USA) were employed for quantitative analysis of reactants and products. The reaction mixture was fifteen times diluted with methanol and injected in portions of $10 \mu \mathrm{L}$. As mobile phase Methanol/ $\mathrm{H}_{2} \mathrm{O} / \mathrm{H}_{3} \mathrm{PO}_{4}, 70-100 / 30-0 / 0.1 \%(\mathrm{v} / \mathrm{v})$, was used with a flow rate of $1 \mathrm{~mL}$ 
$\min ^{-1}$. Mobile phases were $70 \%$ methanol for the determination of ascorbyl acetate and caproate, $90 \%$ for caprate and myristate, and $100 \%$ for stearate and oleate. Retention time of vitamin $\mathrm{C}$ was similar, regardless of eluent composition, and it was in range 2.3-2.5 minutes. Retention times of ester derivatives and corresponding acids were as follows: acetate and acetic acid -3.62 and 4.65, caproate and caproic acid -3.95 and 4.86, caprate and capric acid - 3.84 and 4.75, myristate and myristic acid - 3.94 and 4.79, stearate and stearic acid 6.13 and 7.88, and oleate and oleic acid -3.53 and 4.54. UV detection of products and vitamin $\mathrm{C}$ was done at $235 \mathrm{~nm}$, while fatty acids were detected at $210 \mathrm{~nm}$.

\subsection{Purification of reaction products}

Reaction mixture, filtered and evaporated under reduced pressure, was ten times diluted in acetonitrile and subjected to Akta Purifier HPLC system equipped with fraction collector. Semi preparative reversed-phase C18 column (HYPERSIL GOLD $5 \mu \mathrm{m}$ ODS, 10 x $250 \mathrm{~mm}$, Thermo Fisher Scientific, Waltham, MA, USA) was used. The injection volume was $1 \mathrm{~mL}$. Mobile phase was, depending on ascorbyl ester, 70-95\% acetonitrile in $0.1 \%(\mathrm{v} / \mathrm{v})$ formic acid. The flow rate was $6 \mathrm{~mL} \mathrm{~min}^{-1}$ while the wavelength at which the detection was done was $235 \mathrm{~nm}$. The peak fractions $(0.5 \mathrm{~mL}$ volume $)$ of products were collected by fraction collector and fractions with pure compounds were retested in analytical column, merged, and evaporated to constant mass. Pure esters were used for the DPPH assay and as standards for the quantification of the products.

\subsection{Antioxidant activity assay}

The antioxidant activities of synthesized and purified esters, L-ascorbic acid, and commercial ascorbyl palmitate were determined using DPPH method. This method is based on the ability of tested compounds to reduce stable DPPH radical by accepting an electron. The reaction mixture consisted of $200 \mu \mathrm{L}$ of DPPH solution ( $0.15 \mathrm{mM}$ in metanol), $200 \mu \mathrm{L}$ of sample (concentrations varied in the range $0-5 \mathrm{mg} \mathrm{L}^{-1}$ ), and $600 \mu \mathrm{L}$ of methanol. Control samples 
were composed of $200 \mu \mathrm{L}$ of DPPH solution and $800 \mu \mathrm{L}$ of methanol. Mixtures were vortexed for 2 minutes and left in dark at room temperature for 30 minutes. Absorbances were measured at $517 \mathrm{~nm}$ using spectrophotometer (Ultrospec 330 pro, Amersham Bioscience, Freiburg, Germany), and the precentage of radical scavenging activities were calculated according to the following equation:

\% scavenging $[D P P H]=\frac{A_{c}-A_{s}}{A_{c}} \cdot 100$

where $A_{c}$ represents absorbance of control sample, and $A_{s}$ is absorbance of the tested sample. All corresponding radical scavenging activities were calculated and expressed as $\mathrm{IC}_{50}$, which represent antioxidant concentration necessary to decrease the initial concentration of DPPH radical to $50 \%$.

\subsection{Statistical analyses}

All experiments (ester syntheses and determination of antioxidant activity) were carried out in duplicate. Significance of all investigated parameters in examined ranges for chosen outputs was determined at $p<0.05$ using ANOVA (One-Way Analysis of variance) and Student t-test. Microsoft Office Excel 2007 (Microsoft Corporation, WA, USA) was applied for all analyses. High level of reproducibility was achieved, since standard deviations were less than $5 \%$ in all experiments. In the control samples for enzymatic reaction (prepared and incubated in same way but without addition of enzyme) the product was not detected. Results in Figures and Table are presented as average values \pm standard deviations. 


\section{Results and discussion}

\subsection{Selection of organic solvent}

Lipases have high activity and stability in various organic solvents, which makes them very popular for synthesis in micro-aqueous media. Generally, in the majority of studies of the effect of solvent type was reported that solvents with higher $\log \mathrm{P}$ values are more adequate for ester synthesis [13-15]. Nevertheless, generalization cannot be applied to the synthesis of ascorbyl esters due to the hydrophilic nature of one substrate (L-ascorbic acid). In this study, both hydrosoluble and liposoluble acyl donors were used (log P values from -3.5 to 8.2 ) and organic solvents with a wide range of $\log \mathrm{P}$ values were examined as a reaction media. ANOVA test confirmed that both parameters (fatty acid type and solvent polarity) are highly significant in synthesis of ascorbyl esters $(p<<0.01)$.

Results obtained in our study (Fig. 1) demonstrate that, regardless of the fatty acid polarity, reaction occurred in only three of examined solvents: $t$-butanol, acetonitrile, and acetone. On the other hand, in $n$-hexane and isooctane, esters were not detected, in spite of the fact that these solvents are usually the best choice for ester synthesis, probably due to the lower solubility of ascorbic acid. The most elaborate study of the organic solvent effect was performed by Song and Wei [16], where the synthesis of ascorbyl oleate in eight organic solvents in range of $\log \mathrm{P}$ values between -0.24 and 3.50 was analyzed. The reaction product was determined only in $t$-amyl alcohol. In ethanol, which has similar log $\mathrm{P}$ value $(-0.24)$ to acetone, ascorbyl ester was not detected. Generally, the majority of studies was conducted with tertiary alcohols ( $t$-amyl alcohol or $t$ - butanol), since highest yields, ranging from 20 to $45 \mathrm{~g} \mathrm{~L}^{-1}$ were achieved in tertiary alcohols using various acyl donors [16-18]. Solvents with negative $\log \mathrm{P}$ values were seldomly applied. Adamczak et al. produced $12 \mathrm{mM}$ of ascorbyl oleate in acetone in the presence of molecular sieves, and higher conversions were accomplished in a transesterification of vitamin $\mathrm{C}$ with methyl oleate [19]. Also, Hsieh and 
coworkers achieved yield of $11 \mathrm{mM}$ in acetone by using an activated acyl donor [20]. When ascorbyl acetate was synthesized in reaction between two polar substrates, vitamin $\mathrm{C}$ and vinyl acetate, acetonitrile and acetone turned out to be suitable solvents [21].

Fig 1.

Although in $t$-butanol the highest conversions were accomplished, further study was carried out in acetone. It was mainly because yields accomplished in our experiments in acetone were among highest reported. Also, lower price and higher volatility of acetone makes it more economically favorable comparing to $t$-butanol, since high volatility offers possibility of simpler and less expensive downstream processing. Additionally, acetone has been rated as a GRAS (Generally Recognized as Safe) substance when present in food products at concentrations up to $8 \mathrm{mg} \mathrm{L}^{-1}$.

\subsection{The fatty acid effect on product yield}

Different lipases show selectivity towards FAs (fatty acids) with distinctive chain length as acyl donors in synthesis of ascorbyl esters. Stamatis et al. showed that CAL B exhibited high selectivity towards FAs with chain length of 12 to 18 carbon atoms, when their ascorbyl esters were synthesized, whereas better results were accomplished with acyl donors with shorter hydrocarbon chain [22]. On the other hand, it has been reported that Novozym ${ }^{\circledR} 435$ was selective towards FAs with longer chain, when lauric (C12), palmitic (C16), and stearic (C18) acid were examined as acyl donors in ascorbyl esters synthesis [23]. Both yield and initial reaction rate increased with increase of acyl donor unsaturation degree, as well. Similar trend was observed by Yan et al., while Watanabe and coworkers found no effect of fatty acid chain length on conversion degree [5, 24]. 
Fig 2.

In this study, saturated fatty acids with different chain length (C2, C6, C10, C14, and C18) and unsaturated C18 (oleic) acid were tested as acyl donors using acetone as reaction medium at $55{ }^{\circ} \mathrm{C}$ (Fig. 2). Unlike previous researches in which influence of fatty acid chain length on lipase-catalyzed ascorbyl ester synthesis was investigated, our examination included short chain FAs. Thus, esters of very distinctive polarity, which could extend their potential field of application, were obtained. According to ANOVA test, fatty acid chin length is a highly significant parameter $(p<<0.01)$. Slightly higher conversions were accomplished when short and medium chain saturated FAs had been applied and highest yield was achieved when acetic acid was used. Although it has been previously reported that lipases could be inactivated by acetic acid, there are studies in which acetic acid was successfully applied as acyl donor for various ester synthesis catalyzed by CAL B, which is in accordance with our results [25-27]. Similar trend, the decrease of ester yield with the increase of acyl donor chain length, was reported by Salem et al. when wide range of acyl donors (C4-C18) was examined in the acylation of isoquercetin catalyzed by the Novozym ${ }^{\circledR} 435$ [28]. Such a trend indicates that research in ascorbyl ester synthesis should not be focused only to long chain FAs, since esters of lower molecular mass widen the area of their application. Although their ascorbyl esters are not highly liposoluble, they can be used as antioxidants in bulk oil media, emulsions, and liposomes. Also, according to HLB number, ascorbyl caprate could be applied as a wetting agent and surfactant in $\mathrm{O} / \mathrm{W}$ emulsions. However, used biocatalyst showed good affinity towards long chain fatty acids, as well. In addition, with oleic acid, which possess the same number of carbon atoms as stearic acid but it is monounsaturated, conversion was highest achieved, among all examined fatty acids, when other experimental conditions were kept constant. Student t-test for stearic and oleic acid demonstrated that presence of double bond in hydrocarbon chain is significant factor $(p=0.015)$. It is well known fact that 
lipophilicity of ascorbyl esters increase when more hydrophobic fatty acids are used as acyl donors, which makes them more efficient as additive in lipophilic food products at low concentrations and biosurfactant, particularly in W/O emulsions. Additionally, ascorbyl esters with double bonds in hydrocarbon chain are more soluble in hydrophobic products compared to saturated ones, and therefore, better antioxidants when applied in them.

\subsection{Antioxidant activity of different ascorbyl esters}

Antioxidant activity of six synthesized esters, ascorbic acid, and commercial ascorbyl palmitate was determined by using the DPPH method and obtained results are summarized in Table 1. All examined esters showed high free radical scavenging capacity. However, statistically significant differences in their performances as antioxidants were revealed by ANOVA test $(p<<0.01)$. Ascorbyl acetate, caproate, caprate, and oleate, had better antioxidant characteristics comparing to vitamin $\mathrm{C}$ itself. By analyzing calculated $\mathrm{IC}_{50}$ values, a certain trend could be observed. By increasing the number of carbon atoms in acyl group of ester from 2 to 18 , efficiency of examined antioxidants decreases. Within previous researches, substantially different conclusions regarding antioxidant activity of L-ascorbyl esters were made, in comparison with each other and present study. Nostro et al. claimed that wide range of ascorbyl esters derived from saturated fatty acids (C8-C18) had very similar antioxidant properties which were almost unchanged comparing to parent molecule, vitamin C, by applying DPPH method [29, 30]. On the other hand, it has been previously reported that L-ascobic acid possess DPPH radical scavenging capacity 10 times higher than ascorbyl palmitate and 100 times higher than mixture of ascorbyl esters obtained from palm oil [17]. Interestingly, among esters synthesized by using long chain FAs, ascorbyl oleate (monounsaturated acyl group) showed considerably higher antioxidant activity than ascorbyl esters obtained using saturated FAs (myristic, palmitic, and stearic) as acyl donors. It is possible that oleic acid itself possess "antioxidant-like" effect, which makes its ascorbyl ester 
a very efficient antioxidant or that solubility improvement conferred by the oleyl chain to the corresponding ascorbyl ester made oleate better antioxidant compared to the saturated ones. Such result was somewhat expected since several authors confirmed high potential of Lascorbyl oleate as antioxidant [18, 31, 32]. For example, Viklund et al. reported that ascorbyl oleate was more efficient than palmitate in preservation of the rapeseed oil from the peroxide development which is in line with the results obtained by Song et al. claiming that ascorbyl oleate had a better protective effect on human umbilical cord vein endothelial cells comparing to the other ascorbyl derivatives [31,32]. At the same time, Reyes-Duarte and coworkers demonstrated that ascorbic acid 6-O derivatives, palmitate and oleate, had similar antioxidant efficiency, although slightly lower than vitamin $\mathrm{C}$, by using TEAC assay and accelerated Rancimat test [18].

Table 1.

\subsection{Optimization of lipase-catalyzed synthesis of ascorbyl esters}

Results of previous experiments demonstrated that among all examined acyl donors, oleic acid gave highest yield. In addition, ascorbyl oleate showed great potential as liposoluble antioxidant since its free radical scavenging was more than two times higher comparing to commercial L-ascorbyl palmitate. Hence, in next experimental series focused on optimization of key experimental factors - temperature, lipase loading, concentration of substrates, and water content on the course of the reaction and equilibrium molar conversion, ascorbyl oleate was used as model system.

\subsubsection{The effect of temperature}

Lipase catalyzed esterifications, depending on the enzyme properties, solvent volatility, substrates and product nature, could be conducted at various temperatures. In the majority of reports, CAL B showed maximum activity at temperatures as high as $70{ }^{\circ} \mathrm{C}$. When it comes to synthesis of ascorbyl esters, wide range of temperatures, from 30 to $70{ }^{\circ} \mathrm{C}$, were 
determined to be optimal, when the same enzyme was applied [33-35]. Song and Wei performed esterification of ascorbic and oleic acid with immobilized lipase from Candida sp. and the highest initial rates were achieved at $60{ }^{\circ} \mathrm{C}$ while maximum ester yield was accomplished at $55^{\circ} \mathrm{C}[16]$.

Within this research, the effect of reaction temperature on the initial esterification rate and product concentration was examined in a range between 40 and $55{ }^{\circ} \mathrm{C}$. When temperature was increased, product yield increased from 16.3 to $25.4 \mathrm{mM}$ and initial reaction velocity increased from 0.75 to $1.62 \mathrm{mM} \mathrm{h}^{-1}$, as well. Obtained results were analyzed by ANOVA test, and statistical significance in terms of ester concentration and initial reaction velocity was confirmed $(p<<0.01)$. Hence, maximums were achieved at $55{ }^{\circ} \mathrm{C}$. Further increase of temperature was avoided due to the high volatility of acetone and, therefore, further experiments were conducted at $55^{\circ} \mathrm{C}$.

\subsubsection{The effect of enzyme loading}

Enzyme concentration was varied between $2.5 \mathrm{~g} \mathrm{~L}^{-1}$ and $10 \mathrm{~g} \mathrm{~L}^{-1}$. By using ANOVA test it was confirmed that this parameter significantly affects achieved yields in both short and long reaction times $(p<<0.01)$. It can be seen (Fig. 3.a) that the increase of initial enzyme concentration from 2.5 to $5 \mathrm{~g} \mathrm{~L}^{-1}$ led to a steep increase of initial rate of esterification, but further increase to $10 \mathrm{~g} \mathrm{~L}^{-1}$ showed only minor improvement. Initial concentration of immobilized lipase did not affect the equilibrium of the reaction, but for higher enzyme loadings (5 and $10 \mathrm{~g} \mathrm{~L}^{-1}$ ) time needed for reaching equilibrium was significantly shorter (24 h).

Fig 3.a.

In comparison of the effect of initial enzyme concentration on ester yield per enzyme amount, different trend was observed (Fig. 3.b). Statistical significance of lipase loading on specific yield was demonstrated by ANOVA test $(p<<0.01)$. The maximal amount of product 
obtained per gram of used lipase in these experiments was $6.5 \mathrm{mmol}$, and it was achieved at lowest enzyme concentration $\left(2.5 \mathrm{~g} \mathrm{~L}^{-1}\right)$. It is a promising result, since at similar reaction conditions in the same solvent, Adamczak et al. gained $1.2 \mathrm{mmol}$ of ascorbyl oleate per each gram of used enzyme [19]. Bearing in mind that among all costs of the enzymatic ester production, although total time productivity and energy consumption are significant parameters, the price of the biocatalyst is the highest one, enzyme input of $5 \mathrm{~g} \mathrm{~L}^{-1}$ has turned out to be optimal, since the initial reaction rate and product concentration (Fig. 3.a.) were similar to the highest obtained (at $10 \mathrm{~g} \mathrm{~L}^{-1}$ ). Also, yield of product per amount of enzyme around $4.5 \mathrm{mmol} \mathrm{g}^{-1}$ was reached (Fig. 3.b), which is still higher than in related studies [16, 19]. Therefore, further analyses in our study were obtained at $5 \mathrm{~g} \mathrm{~L}^{-1}$ of lipase.

Fig 3.b.

\subsubsection{The effect of initial substrates concentrations and molar ratio}

In first experimental series, initial concentration of ascorbic acid was varied in the range 0.05-0.2 M, at a fixed molar ratio (1:3) in all experiments. According to ANOVA test, initial concentration of vitamin $\mathrm{C}$ is highly significant parameter within examined range $(p<<0.01)$ in terms of both, molar conversion and ester yield. The highest degree of limiting substrate conversion (20.7 \%) was achieved at lowest concentration (0.05 M) (Fig. 4.a). Further increase of substrate concentration led to the increase of initial rates and lower conversions after $72 \mathrm{~h}$. Therefore, in experiments with higher initial substrate concentration equilibrium conversion was almost reached after $24 \mathrm{~h}$, while at the lowest substrate concentration rise of conversion degree is evident during whole $72 \mathrm{~h}$.

Fig 4.a.

Since the overall space productivity of the reactor should be taken into consideration, the effect of initial substrate concentration on the yield of ascorbyl oleate was examined. The overall yield of product is depicted in Fig. 4.b. The highest concentration of ester was 
achieved at highest initial substrate concentration $(0.2 \mathrm{M})$ and decrease of limiting substrate concentration led to steep decrease of product yield. When Student t-test was performed for the pairs of vitamin $\mathrm{C}$ concentrations, it was revealed that statistically significant difference does not exist only between 0.15 and $0.2 \mathrm{M}$, indicating that this part of examined range could be considered as optimal. This parameter should be also taken into the account during further development of enzymatic processes, since higher product concentration simplifies downstream processing. Higher concentrations of ascorbyl oleate were achieved previously, $50 \mathrm{mM}$ and $45 \mathrm{mM}$, but these experiments were performed in $t$-butanol $[16,18]$. On the other hand, with methyl oleate in acetone $18.9 \mathrm{mM}$ of product was achieved, which is significantly lower than $25 \mathrm{mM}$ obtained in our study [19]. Hence, it seems that our reaction system provides opportunity of product yields comparable with yields obtained with more expensive solvents or acyl donors.

Fig 4.b.

Furthermore, for ascorbic acid concentration that gave the highest conversion, oleic acid concentration was optimized. Previous studies showed that the optimum substrate molar ratio depends on the used acyl donor, and ascorbic acid concentration. However, in most papers, the highest conversions were achieved with excessive amount of acyl donors. Therefore, in our experiments molar ratio was varied in the range 1:1 - 1:15.

It was proven that, by using a great excess of oleic acid, product yield can be considerably increased (Fig. 5). At equimolar conditions only $3.6 \%$ of substrates were converted to an ester, and the excess of oleic acid enabled drastically higher ester yields. Molar ratio of 1:10 turned out to be optimal, since accomplished conversion was $60.5 \%$. Further increase of oleic acid concentration did not lead to higher conversion, probably due to conformational changes of enzyme induced by excessive amount of oleic acid which impeded access of the hydrophilic vitamin $\mathrm{C}$ to the active site of the lipase [17]. Student t-test also showed that no 
statistically significant difference between 10 and 15-fold excess of oleic acid is present, which additionally confirms that increase of substrates molar ratio above 1:10 is not justified.

Fig 5.

\subsubsection{The effect of initial water content}

Water is an unavoidable part of the reaction systems in esterification reactions. All components of reaction mixture have their own water activities $\left(a_{w}\right)$ and overall $a_{w}$ of the whole mixture depend on its composition [36]. Besides that, as a side product of ester synthesis reactions, water is produced. That way, $\mathrm{a}_{\mathrm{w}}$ in reaction medium is being increased during the time. When lipases are used as biocatalysts, an essential water layer that surrounds enzyme molecules is needed for keeping its catalytic activity [37]. However, excessive amount of initial and produced water could be disadvantageous for obtaining high ester yields because it shifts equilibrium position towards the hydrolysis.

Fig 6.

Therefore, in our study influence of the initial water concentration was investigated within the range $0.02-0.12 \%(\mathrm{v} / \mathrm{v})$. ANOVA test confirmed that this parameter is on the border of significance $(p=0.051)$, probably due to the narrowly chosen examination range. However, it can be seen (Fig. 6) that the optimal value of initial water content was $0.07 \%(\mathrm{v} / \mathrm{v})$, with regard to both, initial reaction rate and final product yield. On the other hand, it was previously reported that Novozym ${ }^{\circledR} 435$ showed the highest activity at lowest examined water activities [38-40]. It is possible that highly polar acetone dissolved layer of water that surrounds lipase molecule so some additional water was necessary [41-43]. Also, established water layer can dissolve high concentrations of vitamin $\mathrm{C}$ and increase availability of this substrate nearby the active site of the enzyme.

\subsubsection{Operational stability study}


Share of the enzyme price in the total cost of the biosynthesis processs is usually very high, hence it is of great importance to examine possibility of using the catalyst repetitively. Novozym $^{\circledR} 435$ reusability study was conducted under optimal reaction conditions and it revealed that after ten reaction cycles lasting $24 \mathrm{~h}$, enzyme retained $\sim 50 \%$ of its initial activity, which is satisfying result considering previous reports [44, 45]. Operational stability obtained in our study, therefore, offers good prospects for further development of lipasecatalyzed synthesis of ascorbyl esters.

\section{Conclusion}

In this study was shown that wide range of carboxylic acids can be esterified with ascorbic acid using CALB as biocatalyst with high product yields, since ascorbyl esters were synthesized using six FA substrates (acetic, hexanoic, decanoic, myristic, stearic, and oleic acid). Several organic solvents were tested as a reaction media for the synthesis catalyzed by immobilized lipase from $C$. antarctica. Besides in $t$-butanol, a common solvent for the enzymatic synthesis of ascorbyl esters, significant lipase activity has been observed in solvents with drastically lower log $\mathrm{P}$ values, such as acetone and acetonitrile. Acetone was our solvent of a choice due to its low boiling point and low price, which offered the possibility of developing less expensive industrial enzymatic process. Investigation of the effect of FA chain length on product yield and antioxidant activity of obtained products revealed that ascorbyl esters of saturated fatty acids with shorter chain length were produced in higher yields and they were more powerful antioxidants, as well. However, presence of double bonds in FA was also important hence highest yield was obtained with C18 monounsaturated, oleic acid and improves antioxidant properties with respect to parent molecule, ascorbic acid. Finally, subsequent part of the study was focused on optimization of most important reaction parameters for this ester. Molar conversion was maximized at $55{ }^{\circ} \mathrm{C}$, 
$0.7 \mathrm{~mL} \mathrm{~L}^{-1}$ of initial water, $50 \mathrm{mM}$ of vitamin $\mathrm{C}$, and $0.5 \mathrm{M}$ of oleic acid and it reached 60.5

$\%$. Since this research is conducted using inexpensive solvent, at low concentrations of biocatalyst, and highly efficient liposoluble antioxidants were produced in high yields, obtained results imply very good prospects of lipase-catalyzed synthesis of wide range of FA ascorbyl esters.

\section{Acknowledgements}

The authors are grateful for financial support from the Serbian Ministry of Education, Science, and Technological Development (project III 46010).

The authors declare that there are no conflicts of interest.

\section{Reference}

[1] Karmee, S.K. (2009) Appl. Microbiol. Biotechnol. 81, 1013-1022.

[2] Jayasinghe, C., Gotoh, N., and Wada, S. (2013) Food Chem. 141, 3077-3084.

[3] Karmee, S.K. (2008) Bioproducts and Biorefining 2, 144-154.

[4] Karmee, S.K. (2011) Lipid Technology 23, 227-229.

[5] Yan, Y., Bornscheuer, U.T., and Schmid, R.D. (1999) Biotechnol. Lett. 21, 1051-1054.

[6] Viklund, F., Alander, J., and Hult, K. (2003) J. Am. Oil Chem. Soc. 80, 795-799.

[7] Shi, H., Meng, Y., Yang, M., Zhang, Q., and Meng, Y. (2013) Biotechnol. Appl. Biochem. DOI: 10.1002/bab.1142.

[8] Pan, Y., Tang, K.W., He, C.Q., Yi, W., Zhu, W., and Liu, Y.N. (2013) Biotechnol. Appl. Biochem. DOI: 10.1002/bab.1170.

[9] Bradoo, S., Saxena, R.K., and Gupta, R. (1999) J. Am. Oil Chem. Soc. 76, 1291-1295.

[10] Humeau, C., Girardin, M., Rovel, B., and Miclo, A. (1998) J. Mol. Catal. B: Enzym. 5, $19-23$. 
[11] Humeau, C., Girardin, M., Rovel, B., and Miclo, A (1998) J. Biotechnol. 63, 1-8.

[12] Mateo, C., Palomo, J.M., Fernandez-Lorente, G., Guisan, J.M., and Fernandez-Lafuente,

R. (2007) Enzyme Microb. Tech. 40, 1451-1463.

[13] Hirata, H., Higuchi, K., and Yamahina, T. (1990) J. Biotechnol. 14, 157-167.

[14] Vermue, M.H., and Tramper, J. (1995) Pure Appl. Chem. 67, 345-373.

[15] Yadav, G.D., and Lathi, P.S. (2004) J. Mol. Catal. B: Enzym. 27, 109-115.

[16] Song, Q.X., and Wei, D.Z. (2002) J. Mol. Catal. B: Enzym. 18, 261-266.

[17] Burham, H., Rasheed, R.A.G.A., Noor, N.M., Badruddin, S., and Sidek, H. (2009) J. Mol. Catal. B: Enzym. 58, 153-157.

[18] Reyes-Duarte, D., Lopez-Cortes, N., Torres, P., Comelles, F., Parra, J.L., Peña, S., Ugidos, A., Ballesteros, A., and Plou, F.J. (2011) J. Am. Oil Chem. Soc. 88, 57-64.

[19] Adamczak, M., Bornscheuer, U.T., and Bednarski, W. (2005) Process Biochem. 40, $3177-3180$.

[20] Hsieh, H.J., Chen, J.W., Giridhar, R., and Wu, W.T. (2005) Prep. Biochem. Biotechnol. $35,113-118$.

[21] Zhang, D.H., Li, Y.Q., Li, C., Lv, Y.Q., and Li, Y. (2012) Biotechnol. Bioprocess Eng. $17,60-66$

[22] Stamatis, H., Sereti, V., and Kolisis, F.N. (1999) J. Am. Oil Chem. Soc. 76, 1505-1510.

[23] Song, Q.X., Zhao, Y., Xu, W.Q., Zhou, W.Y., and Wei, D.Z. (2006) Bioprocess Biosyst. Eng. 28, 211-215.

[24] Watanabe Y., Adachi S., Nakanishi K., and Matsuno R. (1999) Food Sci. Technol. Res. $5,188-192$.

[25] Žnidaršič-Plazl, P. and Plazl, I. (2009) Process Biochem. 44 1115-1121.

[26] Güvenç, A., Kapucu, N., Bayraktar, E., and Mehmetoğlu, Ü. (2003) Chem. Eng. Commun. 190, 948-961. 
[27] Claon, P.A. and Akoh, C.C. (1994) J. Am. Oil Chem. Soc.71, 575-578.

[28] Salem, J.H, Humeau, C., Chevalot, I., Schiavo, C.H., Vanderesse, R., Blanchard, F., and Fick, M. (2010) Process Biochem. 45, 382-389.

[29] LoNostro, P., Capuzzi, G., Pinelli, P., Mulinacci, N., Romani, A., and Vincieri, F.F. (2000) Colloid. Surf. A: Physicochem. Eng. Asp. 167, 83-93.

[30] LoNostro, P., Capuzzi, G., Romani, A., and Mulinacci, N. (1999) Langmuir 16, 17441750.

[31] Viklund, F., Alander, J., and Hult, K. (2003) J. Am. Oil Chem. Soc. 80, 795-799.

[32] Song, Q.X., Wei, D.Z., Zhou, W.Y., Xu, W.Q., and Yang, S.L. (2004) Biotechnol. Lett. $26,1777-1780$.

[33] Chang, S.W., Yang, C.J., Chen, F.Y., Akoh, C.C., and Shief, C.J. (2009) J. Mol. Catal. B: Enzym. 56, 7-12.

[34] Lerin, L.A., Richetti, A., Dallaro, R., Treichel, H., Mazutti, M.A., Oliveira, J.V., Antunes, O.A.C., Oestreicher, E.G., and de Oliveira, D. (2012) Food Bioprocess Tech. 5, 1068-1076.

[35] Lv, L.X., Chen, S.Y., and Li, Y.Q. (2008) J. Sci. Food Agric. 88, 659-666.

[36] Chamouleau, F., Coulon, D., Girardin, M., and Ghoul, M. (2001) J. Mol. Catal. B: Enzym. 11, 949-954.

[37] Chen, J.P. (1996) J. Ferment. Bioeng. 82, 404-407.

[38] Ognjanović, N., Bezbradica, D., and Knežević-Jugović, Z. (2009) Bioresour. Technol. $100,5146-5154$.

[39] Salis, A., Pinna, M., Monduzzi, M., and Solinas, V. (2005) J. Biotechnol. 119, 291-299.

[40] Tamalampudi, S., Talukder, M.R., Hama, S., Numata, T., Kondo, A., and Fukuda, H. (2007) Biochem. Eng. J. 39, 185-189.

[41] Zaks, A. and Klibanov, A.M. (1988) J. Biol. Chem. 263, 8017-8021. 
[42] Valivety, R.H., J. Halling, P., and Macrae, A.R. (1992) BBA-Protein Struct. M. 1118, 218-222.

[43] Valivety, R.H., Halling, P.J., Peilow, A.D., and Macrae, A.R. (1992) BBA-Protein Struct. M. 1122, 143-146.

[44] Hari Krishna, S., Divakar, S., Prapulla, S.G., and Karanth, N.G. (2001) J. Biotechnol. 87, 193-201.

[45] Yadav, G.D. and Lathi, P.S. (2003) Biochem. Eng. J. 16, 245-252. 
Figure 1. Influence of organic solvent on ester yield. The reactions were carried out at $55{ }^{\circ} \mathrm{C}$ for $24 \mathrm{~h}$, with $0.2 \mathrm{M}$ of vitamin $\mathrm{C}$ and $0.6 \mathrm{M}$ of fatty acid, with $10 \mathrm{~g} \mathrm{~L}^{-1}$ of lipase and $1.2 \mathrm{~mL}$ $\mathrm{L}^{-1}$ of water in $10 \mathrm{~mL}$ of the reaction medium.

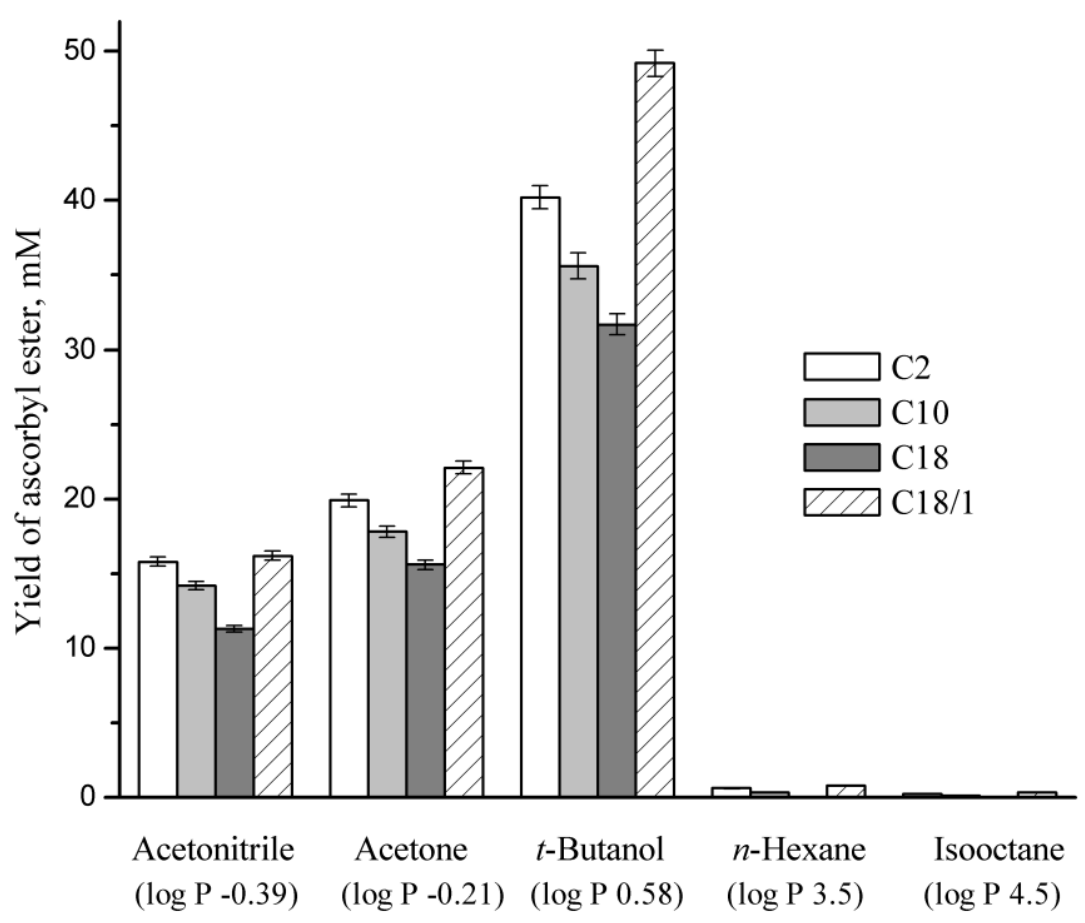


Figure 2. Influence of the acyl donor structure on molar conversion in acetone. The reactions were carried out for $72 \mathrm{~h}$, with $0.05 \mathrm{M}$ of vitamin $\mathrm{C}$ and $0.15 \mathrm{M}$ of fatty acid, with $10 \mathrm{~g} \mathrm{~L}^{-1}$ of lipase and $1.2 \mathrm{~mL} \mathrm{~L}^{-1}$ of water in $10 \mathrm{~mL}$ of the reaction medium.

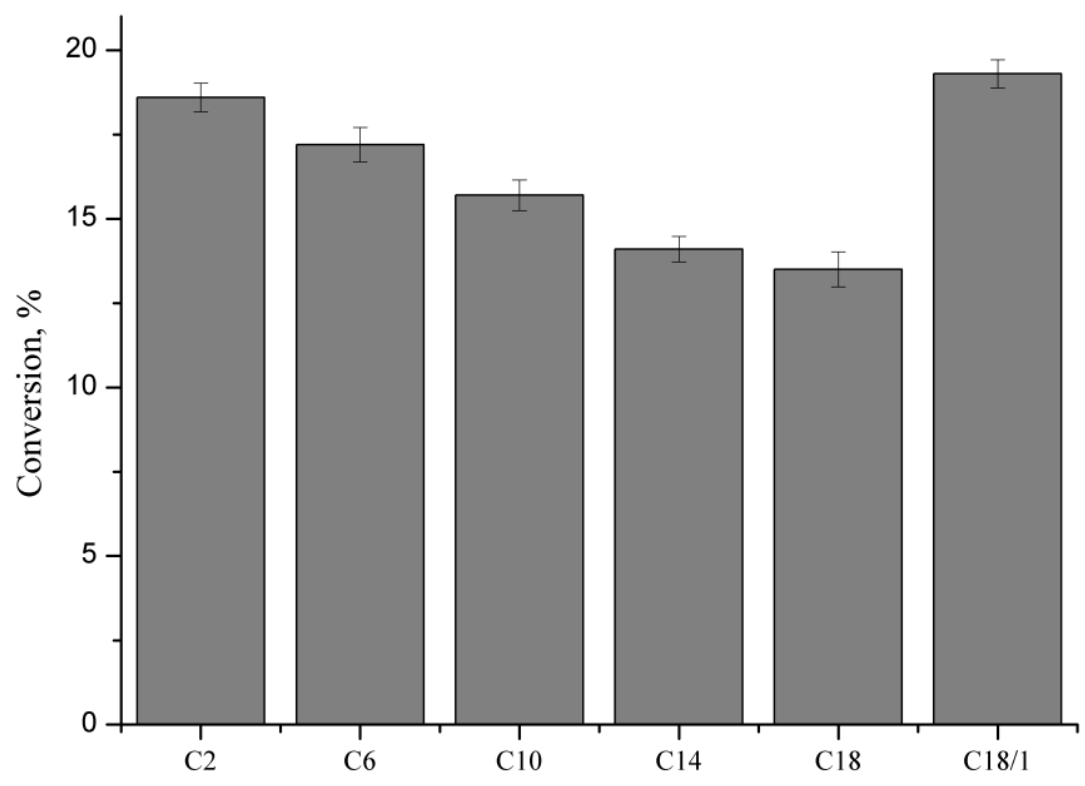


Figure 3.a. Effect of enzyme concentration on product yield. The reactions were carried out at $55^{\circ} \mathrm{C}$ for $72 \mathrm{~h}$, with $0.2 \mathrm{M}$ of vitamin $\mathrm{C}$ and $0.6 \mathrm{M}$ of oleic acid, with $1.2 \mathrm{~mL} \mathrm{~L}^{-1}$ of water in $10 \mathrm{~mL}$ of the reaction medium. Enzyme concentration: $\boldsymbol{\Delta}-2.5 \mathrm{~g} \mathrm{~L}^{-1}, \bullet-5 \mathrm{~g} \mathrm{~L}^{-1}, \boldsymbol{\square}-10 \mathrm{~g} \mathrm{~L}^{-1}$. Figure 3.b. Effect of enzyme concentration on process productivity. The reactions were carried out at $55^{\circ} \mathrm{C}$ for $72 \mathrm{~h}$, with $0.2 \mathrm{M}$ of vitamin $\mathrm{C}$ and $0.6 \mathrm{M}$ of oleic acid, with $1.2 \mathrm{~mL} \mathrm{~L}^{-}$ ${ }^{1}$ of water in $10 \mathrm{~mL}$ of the reaction medium. Enzyme concentration: $\boldsymbol{\Delta}-2.5 \mathrm{~g} \mathrm{~L}^{-1}, \bullet-5 \mathrm{~g} \mathrm{~L}^{-1}$, - $10 \mathrm{~g} \mathrm{~L}^{-1}$.
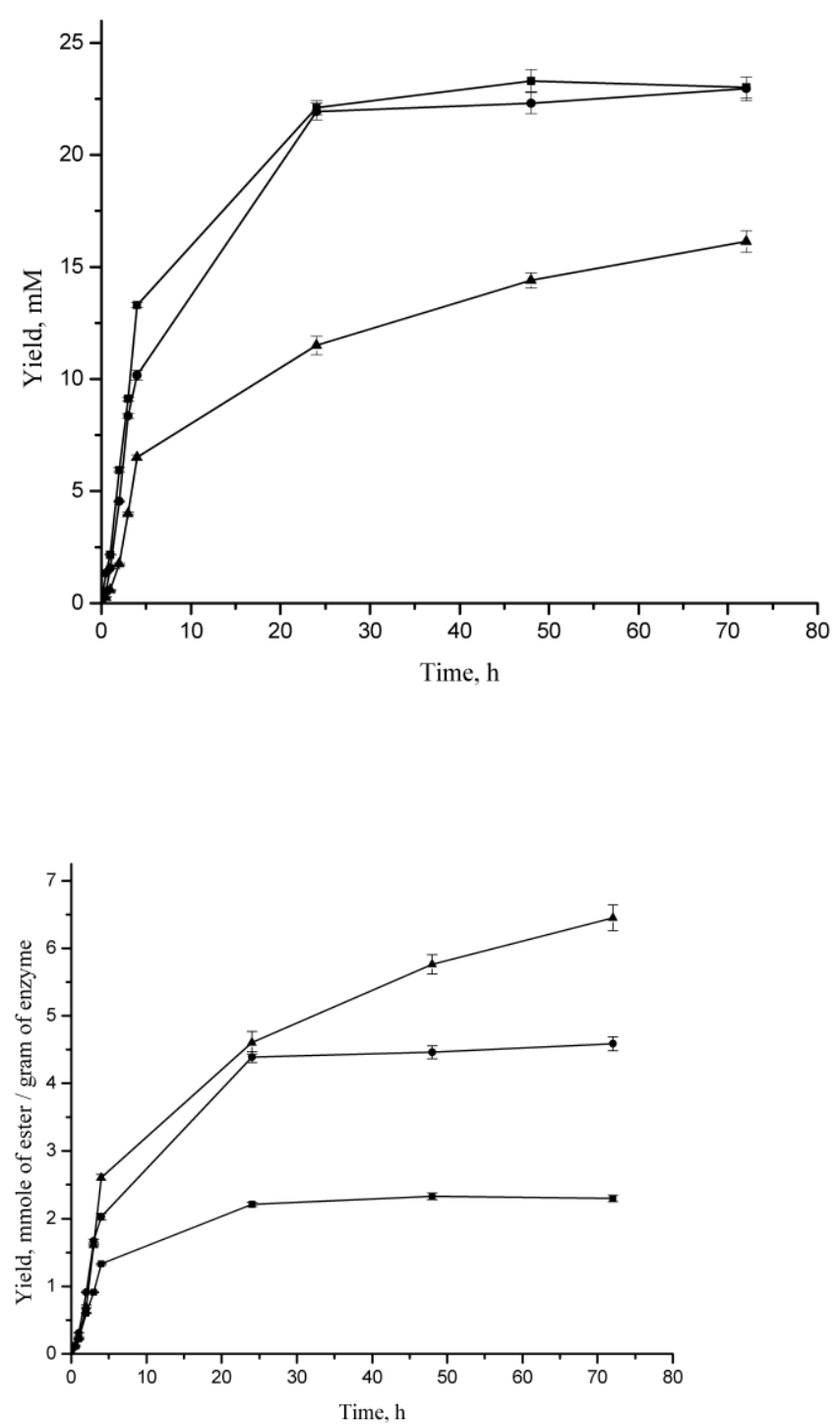
Figure 4.a. Influence of substrates concentrations on conversion. The reactions were carried out at $55{ }^{\circ} \mathrm{C}$ for $72 \mathrm{~h}$, with various substrates concentrations, at 3:1 mole ratio of oleic acid to vitamin $\mathrm{C}$, with $5 \mathrm{~g} \mathrm{~L}^{-1}$ of lipase and $0.7 \mathrm{~mL} \mathrm{~L}^{-1}$ of water in $10 \mathrm{~mL}$ of the reaction medium. Vitamin C concentration: $\boldsymbol{\Delta}-0.2 \mathrm{M}, \bullet-0.15 \mathrm{M}, \boldsymbol{\square}-0.1 \mathrm{M}, \times-0.05 \mathrm{M}$.

Figure 4.b. Influence of substrates concentrations on product yield. The reactions were carried out at $55{ }^{\circ} \mathrm{C}$ for $72 \mathrm{~h}$, with various substrates concentrations, at $3: 1$ molar ratio of oleic acid to vitamin $\mathrm{C}$, with $5 \mathrm{~g} \mathrm{~L}^{-1}$ of lipase and $0.7 \mathrm{~mL} \mathrm{~L}^{-1}$ of water, in $10 \mathrm{~mL}$ of the reaction medium. Vitamin C concentration: $\Delta-0.2 \mathrm{M}, \bullet-0.15 \mathrm{M}, \boldsymbol{\square}-0.1 \mathrm{M}, \times-0.05 \mathrm{M}$.
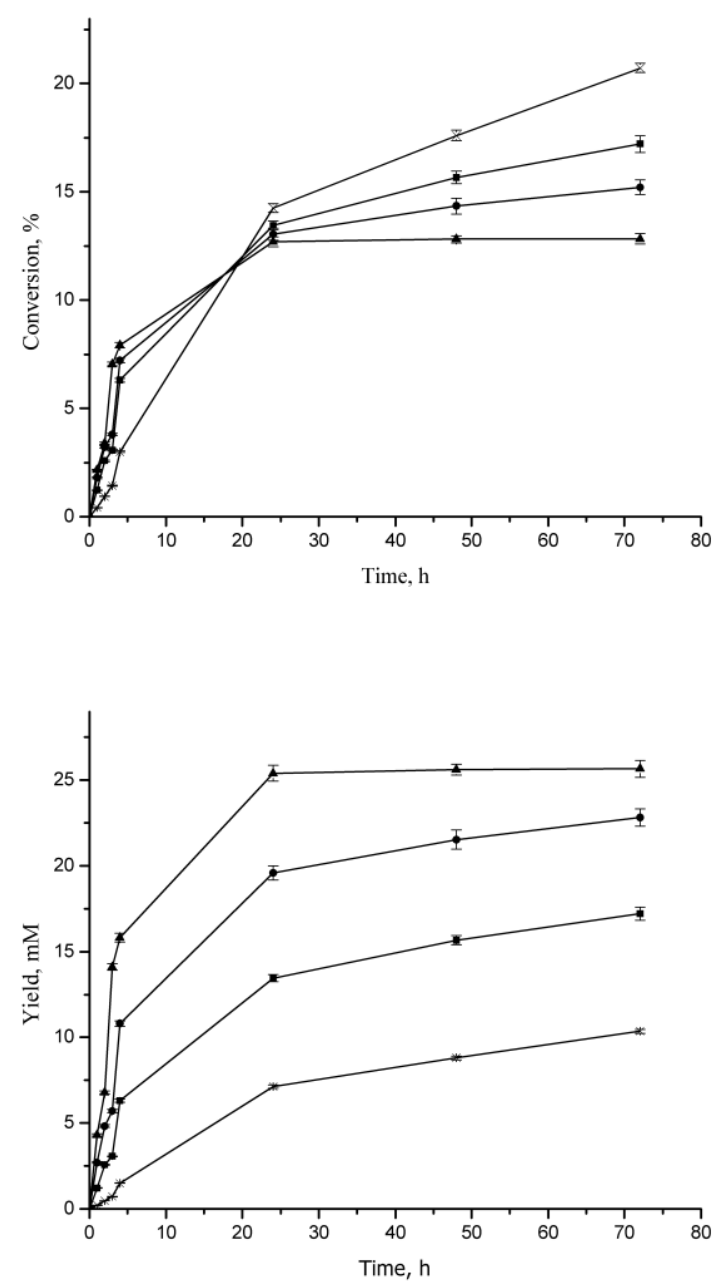
Figure 5. Influence of substrates molar ratio on conversion. The reactions were carried out at $55^{\circ} \mathrm{C}$ for $72 \mathrm{~h}$, with $0.05 \mathrm{M}$ of vitamin $\mathrm{C}$ and various oleic acid concentrations, with $5 \mathrm{~g} \mathrm{~L}^{-1}$ of lipase and $0.7 \mathrm{~mL} \mathrm{~L}^{-1}$ of water in $10 \mathrm{~mL}$ of the reaction medium. Substrates molar ratio:

$-1: 1, \bullet-1: 3$, 匹 $1: 5, \times-1: 7,-1: 10, \circ-1: 15$.

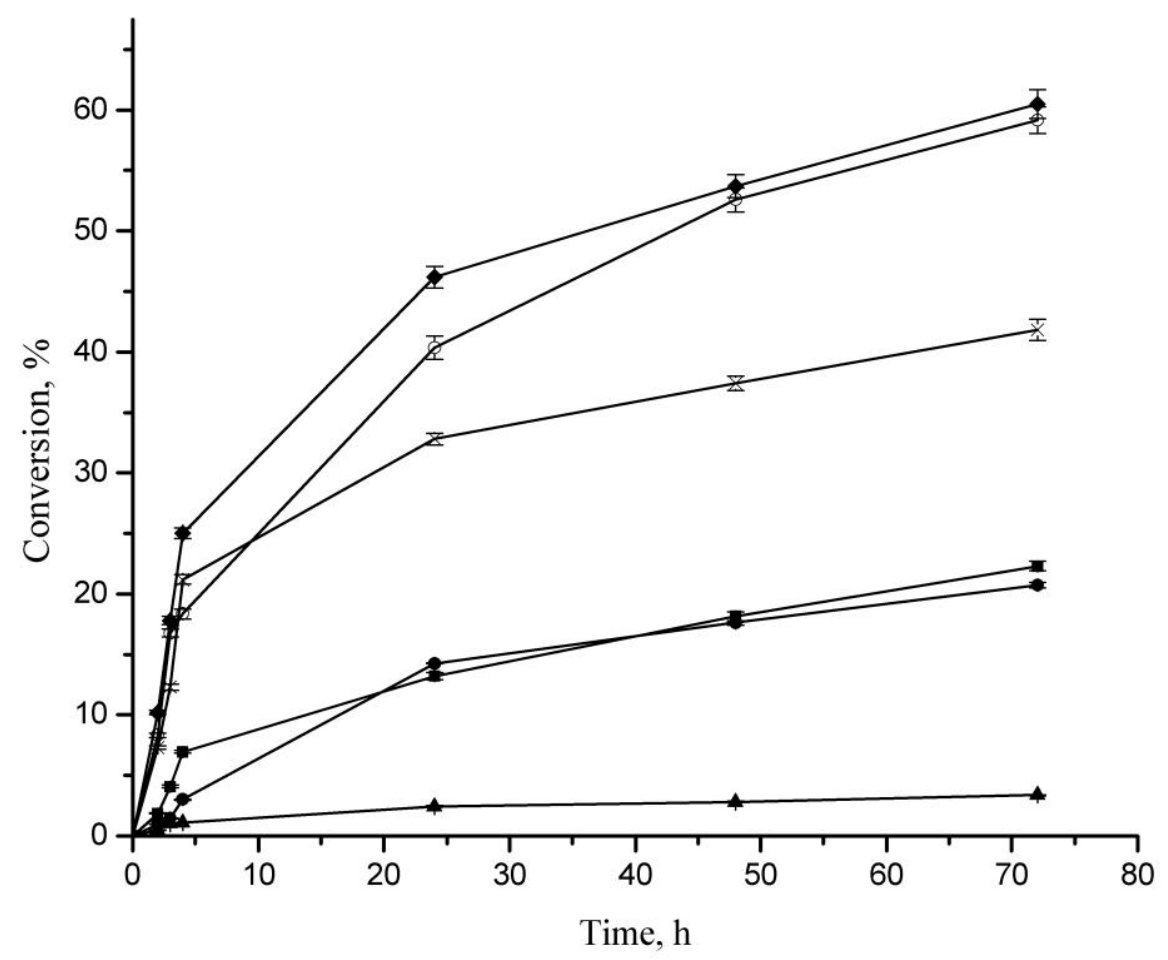


Figure 6. Effect of initial water content. The reactions were carried out at $55^{\circ} \mathrm{C}$ for $72 \mathrm{~h}$, with $0.2 \mathrm{M}$ of vitamin $\mathrm{C}$ and $0.6 \mathrm{M}$ of oleic acid, with $10 \mathrm{~g} \mathrm{~L}^{-1}$ of lipase in $10 \mathrm{~mL}$ of the reaction medium. Initial water content: $\boldsymbol{\Delta}-1.2 \mathrm{~mL} \mathrm{~L}^{-1}, \bullet-0.7 \mathrm{~mL} \mathrm{~L}^{-1}, \mathbf{\square}-0.2 \mathrm{~mL} \mathrm{~L}^{-1}$.

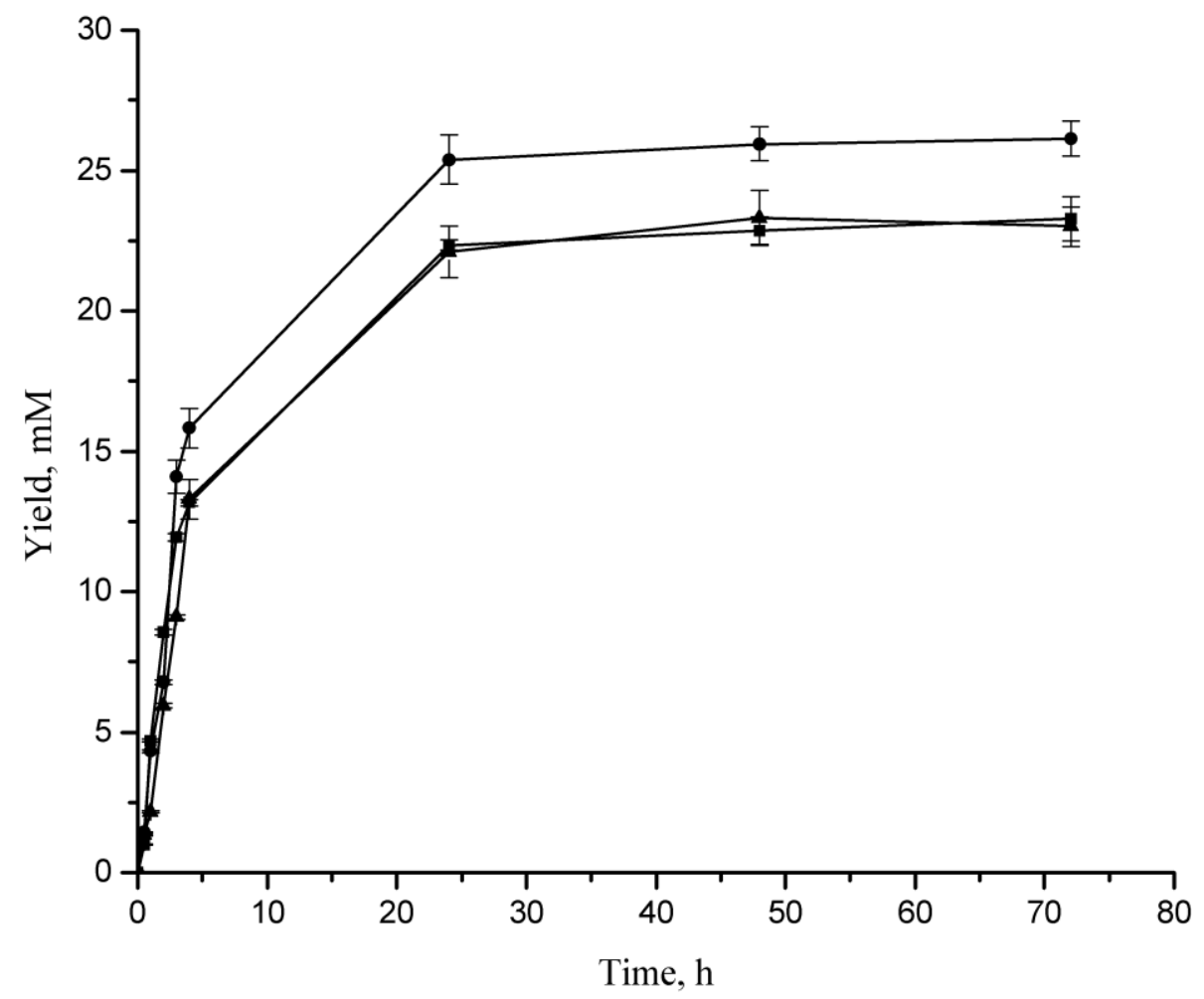


Table 1. Free radical scavenging capacity of ascorbyl esters and L-ascorbic acid

\begin{tabular}{ll}
\hline Compound & IC $_{\mathbf{5 0}}\left(\mathbf{m g ~ L}^{\mathbf{- 1}}\right)$ \\
\hline Ascorbyl acetate & $0.253 \pm 0.007$ \\
Ascorbyl caproate & $0.264 \pm 0.005$ \\
Ascorbyl caprate & $0.715 \pm 0.008$ \\
Ascorbyl myristate & $1.491 \pm 0.014$ \\
Ascorbyl palmitate & $1.548 \pm 0.006$ \\
Ascorbyl stearate & $1.754 \pm 0.018$ \\
Ascorbyl oleate & $0.653 \pm 0.008$ \\
Vitamin C & $0.812 \pm 0.009$ \\
\hline
\end{tabular}

